\section{Plague in India}

EDITOR, - D T Dennis's editorial on lessons to be learnt from the outbreak of bubonic and pneumonic plague in Maharashtra and Gujurat, India, points towards maintenance of the public health infrastructure to detect, monitor, and combat different agents of disease. ${ }^{1}$ That would not be feasible without sound laboratory support in developing countries where government expenditure on drugs is less than five cents per person and health posts run out of their annual supplies of drugs during the early part of the fiscal year. ${ }^{2}$

Intermediate and peripheral level laboratories would fail to identify promptly infection with Yersinia pestis in rodents, fleas, and humans since results of light microscopy, specific fluorescence, and phage lysis of colonies can at best suggest the infection; they would not be confirmatory. ${ }^{3}$ In vitro characterisation of isolates, including the demonstration of pathogenicity in rodent or flea tissues, would not be possible in many clinical or public health laboratories.

Recently, $Y$ pestis was identified by the polymerase chain reaction within four hours with use of oligonucleotide primers specific for the plasminogen activator gene of $Y$ pestis. There was $100 \%$ specificity in the identification of 43 strains isolated from humans, rats, and fleas. ${ }^{4}$ As few as $10 Y$ pestis cells were detected in flea tissue by the polymerase chain reaction by other investigators.

The polymerase chain reaction with primers specific for the plasminogen activator gene needs to be simplified for extensive diagnostic use in developing countries. A simplified format in microtitre wells has been developed for HIV proviral DNA (S Cassel et al, 10th international conference on AIDS, Yokohama, 7-12 August 1994). A similar technique, if standardised for $Y$ pestis, would simplify a specific diagnosis of plague.

Sheep erythrocytes tagged with $Y$ pestis fraction 1 have been used for specific screening of serum from rodents and humans and for qualitative and quantitative assays of antibodies to $Y$ pestis. Paired serum specimens are desirable to show a fourfold rise in the haemagglutination titre for a serological confirmation of plague.

Even though these tagged sheep erythrocytes would ensure specificity, the presence of Forssman antibodies and non-specific haemagglutinins in the animal serum under test could vitiate the specificity of such a test system. Non-specific

We prefer short letters that relate to a recently published article and we are unlikely to publish letters longer than 400 words and containing over five references. Letters may be shortened. Your letters should be typed with double spacing and include a word count. All authors need to sign the letter and provide one current appointment and address. We encourage you to declare any conflict of interest. Please enclose a stamped addressed envelope if you require an acknowledgment. reactions pose innumerable problems since at least 220 species of rodent and 30 species of flea are proved vectors of plague. The non-specific haemagglutination could be eliminated by use of tagged latex particles rather than erythrocytes. Irrespective of whether erythrocytes or latex particles are used, it would be essential to neutralise the observed agglutination in serum under test with $Y$ pestis fraction 1.

SUBHASH C ARYA Clinical microbiologist

Centre for Logistical Research and Innovation,

M-122 Greater Kallash-II,

New Delhi 110048

India

1 Dennis DT. Plague in India. BMf 1994;309:893-4. (8 October.)

2 World Bank. World bank atlas. Washington, DC: World Bank, 1990

3 Doll JM, Zeitz PS, Allested P, Bucholtz AL, Davis T, Gage K. Cat-transmitted pneumonic plague in a person who traveled from Colorado to Arizona. Am f Trop Med Hyg 1994;51: 109-14.

4 Cambell J, Lowe J, Walz S, Ezzell J. Rapid and specific identification of Yersinia pestis by using a nested polymerase identification of Yersinia pestis by using a nested polymer.

5 Hinnebush J, Schwan TG. New method for plague surveillance using polymerase chain reaction to detect Yersinia pestis in using polymerase chain reaction to
fleas. $f$ Clin Microbiol 1993;31:1511-4.

\section{Infectivity of pneumonic plague}

EDIToR,-In a press release issued by the Department of Health the chief medical officer, Dr Kenneth Calman, stated that the risk of person to person transmission of pneumonic plague was considered to be low'; this opinion has been reiterated during numerous interviews in the media. Dr Calman is also quoted by Claudia Court as saying that it is rare for plague to be transmitted person to person. ${ }^{2}$ Dr Barbara Bannister ascribes this low infectivity to the larger, heavier sputum particles that she believes are produced in pneumonic plague. ${ }^{2}$

These comments are at variance with our understanding of pneumonic plague as a highly infectious disease. Our training has taught us this, and we in turn teach it to others. A glance at many textbooks on infectious diseases or microbiology will support this view. Christie refers to pneumonic plague as "highly infectious and highly lethal" and comments on the quality of the sputum as "watery, not viscid, teeming with Yersiniae." The recommendations of the United States Centers for Disease Control state that pneumonic plague may be highly contagious and that untreated plague pneumonia is an epidemiological emergency. ${ }^{4}$

Reports of outbreaks of pneumonic plague provide further evidence of its high infectivity. For example Tieh et al described such an outbreak in Mukden, China, in which the index patient infected five casual acquaintances at a dinner and then, through a cascade of contacts, a further 34 people were infected within one month. All but three died, including the medical attendant of one of the patients.

We agree that the possibility of a major outbreak of pneumonic plague in Britain is remote because of heightened awareness and the relatively sophisticated epidemiological surveillance system that is in place. To say that an outbreak of pneumonic plague is unlikely, however, is quite different from saying that the disease is of low infectivity. Such comments may send the wrong message to travellers who are at risk of coming into contact with a person proved to have or suspected of having the disease and may have the effect of lowering their vigilance.

PETER COWLING Senior registrar

Department of Microbiology,

Royal Hallamshire Hospital,

Sheffield S10 2JF

Department of Infectious Disease

PETER MOSS

Senior registrar

1 Department of Health Press Office. Outbreak of plague in Gujarat, India-chief medical officer gives advice. London: DoH, 1994. India-chief medical Prfecr gives advice. London: DoH, 1994. 897-8. (8 October.)
Court C. Plague prom

3 Christie AB. Infectious diseases. Epidemiological and clinical practice. 3rd ed. Edinburgh: Churchill Livingstone, 1980:762.

4 White ME, Gordon D, Poland JD, Barnes AM. Recommendations for the control of Yersinia pestis infections. Recommendations from the CDC. Infection Control 1980;1:324-9.

5 Tieh TH, Landauer E, Miyagawa F, Kobayashi G, Okayasu G. Primary pneumonic plague in Mukden, 1946, and report of 39 cases with 3 recoveries. $\mathcal{F}$ Infect Dis 1948;82:52-8.

\section{The sight test fee}

\section{Effectiveness of treatment for glaucoma remains unproved}

EDrToR,-D A H Laidlaw and colleagues are concerned that the prevalence of blindness due to glaucoma may increase because of reduced uptake of screening since the introduction of the sight test fee. ${ }^{1}$ Their implication is that treatment improves outcome. Unfortunately, the effectiveness of treatment for glaucoma remains unproved. Eddy and Billings, in a comprehensive review of the literature, found "not a single book, chapter or paper that systematically reviewed the evidence on the effectiveness of [glaucoma] treatment." A 20 year follow up of the outcome of surgery for glaucoma (trabeculectomy) was unable to show field stability irrespective of the intraocular pressure. ${ }^{3}$ Holmin et al, in a small trial of medical treatment versus no treatment, found no significant difference in field decay between the groups. ${ }^{4}$ The authors of this study ironically noted, "that a very high pressure tends to impair the circulation and lead to atrophy of the optic nerve head is undeniable. The idea of extrapolating this fact to be valid even in the lowest pressure range may appear logical and even so seductive that testing of the hypothesis is found unnecessary."

Adequate proof of the benefit of treatment for glaucoma is long overdue.

LOUIS CLEARKIN Consultant ophthalmic surgeon

Arrowe Park Hospital

Upton

Wirral,

Merseyside L49 5PE

1 Laidlaw DAH, Bloom PA, Hughes AO, Sparrow JM, Marmion VJ. The sight test fee: effect on ophthalmology referrals and rate of glaucoma detection. BMf 1994;309:634-6. (10 September.)

2 Eddy D, Billings $\mathrm{J}$. The quality of medical evidence and medical practice. Washington: National Leadership Commission on Health Care, 1987

3 Watson PG, Jakeman C, Ozturk M, Barnett MF, Barnett F, Khaw KT. The complications of trabeculectomy (a 20 year follow-up). Eye 1990;4:425-38.

4 Holmin C, Thorburn W, Krakau C. Treatment versus no treatment in chronic open angle glaucoma. Acta Ophthalmol 1988;66:170-3. 